\title{
Violência Escolar e Paz numa perspectiva Subjetiva: um estudo a partir da vivência e religiosidade de alunos do último ano do Ensino Fundamental
}

\author{
Marcelo Máximo Purificação ${ }^{1}$; Elisângela Maura Catarino ${ }^{2}$; Eduardo Gusmão de Quadros ${ }^{3}$
}

Resumo: Este estudo integrado na problemática geral da violência escolar e a necessidade de cultura de paz, faz parte da pesquisa desenvolvida no Programa de Doutorado em Ciências da Religião realizado na PUC-Goiás (2010-2014), cujo objetivo foi compreender as relações estabelecidas no ambiente escolar, o conceito e os tipos de violência e propagar a ideia da possibilidade de uma cultura de paz, a partir da representatividade do Sagrado construída na concepção de alunos do último ano do Ensino Fundamental de uma escola estadual em Luziânia Goiás. Os procedimentos metodológicos perpassam por uma perspectiva histórico social multidisciplinar, embasados em pesquisa de cunho qualitativa e quantitativa. O diálogo teórico materializa em discussões com autores da Ciências da Religião, Educação, História, Filosofia, Sociologia e Teologia. À guisa de conclusão, entende-se, que as relações violentas são construídas nos contextos sociais e quando ocorridas na educação, promove o desinteresse e a insegurança no ambiente escolar. A representação do Sagrado materializado na voz dos sujeitos na PAZ pressupõe na escola toda forma de exclusão e a política de uma vivência harmoniosa.

Palavra-chave: Violência Escolar. Cultura de Paz. Experiência Religiosa. Subjetividade.

\section{School Violence and Peace in a Subjective Perspective: a study based on the experience and religiosity of seniors in elementary school}

\begin{abstract}
: his study, integrated in the general problem of school violence and the need for a culture of peace, is part of the research carried out in the Doctoral Program in the Sciences of Religion held at PUC-Goiás (20102014), whose objective was to understand the relations established in the environment School, the concept and types of violence and to propagate the idea of the possibility of a culture of peace, based on the representativeness of the Sacred, built in the conception of the last year of Elementary School of a state school in Luziânia - Goiás. Are based on a multidisciplinary social historical perspective, based on qualitative and quantitative research. The theoretical dialogue materializes in discussions with authors of the Sciences of Religion, Education, History, Philosophy, Sociology and Theology. By way of conclusion, it is understood that violent relationships are built in social contexts and when they occur in education, it promotes disinterest and insecurity in the school environment. The representation of the Sacred materialized in the voice of the subjects in PEACE presupposes in the school every form of exclusion and the politics of a harmonious experience.
\end{abstract}

Words Key: School Violence. Culture of Peace. Religious Experience. Subjectivity.

\footnotetext{
${ }^{1}$ Pós-Doutor em Educação pela Faculdade de Psicologia e Educação da Universidade de Coimbra. Doutor em Ciências da Religião. Professor Titular na UNIFIMES. Líder do Grupo de Estudo e Pesquisa em Psicologia, Neurociências e Educação (GEP - PNEdu) CNPq/UFMS, Coordenador do grupo de Estudos, Pesquisa e Extensão Multidisciplinar - (NEPEM) -CNPq/UNIFIMES. E-mail: maximo@fimes.edu.br

${ }^{2}$ Pós-Doutora em Educação pela Escola Superior de Educação de Coimbra. Doutora em Ciências da Religião. Professora Titular na UNIFIMES. Coordenadora da Linha de Pesquisa: Processos Educativos do Grupo de Estudos, Pesquisa e Extensão Multidisciplinar (NEPEM) - CNPq/UNIFIMES. Email: maura@ fimes.edu.br

${ }^{3}$ Doutor em História. Professor Titular na Universidade Estadual de Goiás e na Pontifícia Universidade Católica de Goiás. Pesquisador nos Grupos de Pesquisa Religião, Cultura e Sociedade; Cultura, Poder e Representações; Núcleo de Estudos Avançados Religião e Globalização - CNPq/PUC-Goiás. E-mail: eduardo.hgs@hotmail.com
} 


\section{Introdução}

A religião se apresenta na vida do indivíduo como um repertório de significações indispensáveis para o enfrentamento dos problemas vivenciados no dia a dia e até mesmo das questões ditas existenciais, além de atuar fortemente na construção da identidade dos sujeitos. Por isso, "não há como pensar o processo de construção da identidade sem que haja uma relação com o processo de socialização, uma vez que é por meio da interação social que ela se constrói” (DUBAR, 1997, p. 13).

Por conseguinte, a presente pesquisa sobre violência e cultura de paz no contexto escolar parte das concepções dos sujeitos sobre o que é violência, Deus e paz. A proposta é um convite à subjetividade expressa na organização escolar e desenvolvida por meio dos "processos e estruturas simbólicas que ajudam na construção dos significados institucionais" (BERGER; LUCKMANN, 2003, p. 78).

A partir das concepções desses alunos sujeitos desta pesquisa encontramos um universo de simbolismos, que consistem "no último nível de legitimação e o mais amplo e complexo", pois são matrizes de todos os significados subjetivamente reais. Assim, a identidade subjetiva é fundamentalmente legitimada nesse universo simbólico, ${ }^{4}$ como podemos observar no depoimento que segue:

[Violência é] um ato extremo da ignorância que uma pessoa pode chegar. Pra tudo na vida tem jeito, mas, em meio ao sufoco e ao stress do dia a dia, qualquer coisinha é motivo de discussão, que muitas vezes acaba em agressão física ou verbal. (A-3).

O conceito de violência do referido aluno nos remete a Bourdieu (2003), quando diz que "cada sujeito é subjetivado de acordo com a sua posição e experiências nas estruturas em que vive". Isso confirma a tese de que o conceito de violência na concepção dos sujeitos é construído e determinado em suas relações sociais. Se adentrarmos na compreensão do conceito de habitus de Bourdieu e olharmos a ordem social em que os sujeitos da pesquisa estão inseridos, compreenderemos a constituição da concepção de violência criando novas perspectivas para compreensão desse conceito.

Entrevistas realizadas entre maio e junho de 2013. 
Quando focamos o questionamento para definição e representação simbólica de Deus, encontramos, em meio aos sujeitos, o seguinte: "Deus é tudo que é belo, que transmite amor, paz, perdão. A imagem mais próxima para se definir Deus é a família” (A-9).

Percebe-se na construção do conceito de Deus/Sagrado, a partir da visão do aluno A-9 e, consequentemente, de todos os outros participantes da pesquisa, que a forma de descrever falar do Sagrado - pode se fundamentar nas concepções de Otto (2005), quando afirma: “[...] o Sagrado em suas manifestações se revela na pessoa e para a pessoa”, numa linguagem que só pode ser compreendida de fato pelo próprio sujeito que a sente, pois tal linguagem está imbuída de significações e de qualidades particulares. Nesse contexto, a experiência religiosa e as relações sociais têm o poder de construir e/ou ressignificar seus valores e atitudes no dia a dia.

A dimensão religiosa torna-se parte da pessoa humana, pois ela é simbólica e as suas experiências mais fundantes são divinizadas. Na escola e em todos os setores da sociedade, a pessoa humana é possuída pelo Sagrado e lhe confere várias interpretações, por não ser apenas externo, mas interno ao homem.

Nesse contexto, Galimberti (2003, p. 12) afirma: "o Sagrado é o fundo inconsciente da pessoa humana. Toda pessoa emancipou a sua consciência e tornou-a autônoma a partir do sagrado, sem, contudo, esquecer o cenário enigmático e obscuro da sua origem”.

Para Rizzuto (2006, p. 60), a ideia de Deus é viva na mente humana, como um arquétipo, como uma espécie de caixa vazia que vai sendo preenchida conforme as relações que estabelecemos com o mundo, sobretudo com os pais. As relações parentais que a criança estabelece nos primeiros anos de vida são determinantes para a sua concepção de Deus.

O terceiro eixo aqui investigado é a definição de paz, no campo empírico, a partir da análise do sujeito A-1, que diz: “[Paz] não é necessariamente a ausência de guerra, mas é popularmente definida como tranquilidade, calma. Defino como aquilo que desprende o pensamento do homem para qualquer tipo de problema".

Se partirmos da concepção de Kant (1795), através de sua obra A paz perpétua (1989), entender-se-á que a institucionalização da paz é um compromisso de todos e que há uma necessidade de se criar culturas de paz como forma de contenção e redução da violência. Kant, nessa sua obra, se posiciona a favor das regras, pois, segundo ele, a existência dessas é 
adjutória para a contenção dos propósitos expansionistas de grupos e nações que violam direitos dos cidadãos, culminando-se em guerras e violência.

Diante de toda a gama de discussão criada a partir das concepções dos sujeitos desta pesquisa sobre os conceitos de violência, paz e Deus, entendemos ser a escola um espaço ideal para o desenvolvimento dessas noções. Isso porque a função social da escola é a formação integral do educando.

A estruturação de tudo isso está, para nós, na fala do educador para a paz Marcelo Guimarães (2002, p. 9). Segundo ele, "paz e violência são construções culturais". Isso significa que não são heranças genéticas, mas resultantes de um processo de aprendizagem. E, consequentemente, suscetíveis de reaprendizagem e ressignificação, ou seja, podem ser desaprendidas e transformadas.

\section{Relações entre violência e religião no campo empírico}

É comum ouvirmos no meio acadêmico que a religião é uma forma de controle social. Tal pensamento baseia-se nos ideários de Durkheim, ao afirmar que o efeito da religião "é necessariamente fixar, instituir, certas maneiras de agir e certos julgamentos que existem fora de nós e que não dependem de cada vontade particular tomada à parte" (FORACCHI; MARTINS, 1980, p. 30).

No universo religioso considera-se que a "mentalidade dos grupos não é a mesma dos particulares" (FORACCHI; MARTINS, 1980, p. 26), e que o indivíduo, quando não consegue interagir socialmente dentro dos padrões de sua coletividade, paga de alguma forma por isso. Nesse contexto, a função do comportamento moral tende a responder à necessidade social de regular, cujo foco na verdade era o de normalizar e direcionar as relações dos indivíduos.

Partindo desse pressuposto e voltando para o nosso campo de pesquisa, podemos afirmar que a religião tem sim o poder de conter a violência escolar.

Para Beyer (1998, p. 396), a religião deixou de estar associada apenas a instituições para se associar aos indivíduos, ou seja, as pessoas passaram a identificar a religião como algo pessoal, privado, e não apenas institucional. Destaca que a influência da religião acaba passando por diversas esferas públicas por onde passam os indivíduos, como seu local de 
trabalho ou a escola. E reforça nossa tese de que a religião, dessa forma, acaba afetando o comportamento dos indivíduos, adentrando diversas esferas públicas e garantindo sua existência e multiplicação.

Tomando por base o nosso campo empírico e a análise e interpretação do gráfico a seguir, vamos analisar a relação dos sujeitos desta pesquisa com a religião e tentar entender de que forma essa influência na mudança de comportamento e na atitude dos alunos do $9^{\circ}$ ano da escola-campo.

Ao responderem à enquete "qual a sua religião?", obtivemos dos nossos entrevistados os seguintes resultados:

Gráfico 1: Qual a sua religião?

\begin{tabular}{|l|c|c|c|c|}
\hline & \\
\hline & & & & \\
\hline
\end{tabular}

Fonte: Entrevistas realizadas entre maio e junho de 2013.

Os dados demonstram que a maior parte dos alunos entrevistados, ou seja, $45 \%$, denominam-se católicos, $35 \%$ evangélicos, $6 \%$ espíritas e $2 \%$ de outras religiões. O gráfico mostra, ainda, que os mais atuantes dentro dos movimentos religiosos são os evangélicos, com $85,70 \%$, seguidos dos espíritas, com 83,33\%.

Para melhor entendermos os resultados obtidos na pesquisa, classificamos a violência escolar em "violência na escola" e "violência contra a escola". A explicação dessas modalidades responde à segunda hipótese desta pesquisa: Determinados contextos propiciam o desenvolvimento de manifestações de violência, e essa, quando colocada em ação, revela 
aos atores sociais o poder de seu uso. Assim, uma violência que, inicialmente, se organiza a partir de um contexto favorável produz, ou pode produzir, a violência como lógica de intervenção.

A violência na escola toma corpo e deve ser analisada como violência da escola. A sua manifestação se dá nas mais diversas formas, como por exemplo agressão contra alunos, professores e funcionários da escola. Além dos exemplos citados, transitam também, por esse ambiente, outras formas de violência. As regras e normas, quando não compreendidas, também acabam em conflitos e consequentemente em atos de violência. Percebe-se que, quando as relações sociais são rigidamente hierarquizadas, a violência é um recurso sistemático para a superação dos problemas. Assim, ao invés do funcionamento dos mecanismos institucionais, o que se encontra é uma situação de conflito permeando os espaços escolares. Com isso, aparece a violência velada, silenciosa, mas que deixa suas marcas na escola, como por exemplo os fracassos escolares, os preconceitos (racismo), a desvalorização, a indisciplina, a expulsão, a ameaça, a intimidação, o abuso de poder e outras.

As entrevistas realizadas apontam com detalhes a presença da violência na escola, como exemplificado nas falas que seguem:

O que mais me chamou a atenção nos últimos meses foi uma briga entre duas meninas de 11 para 12 anos por causa de um namorado. Elas se agrediram violentamente. (P-6).

Uma mãe queria bater/agredir a professora por causa da nota da filha. (P-3).

É comum alunos enfrentarem ou desafiar o professor em sala quando esse o chama a atenção. E quando são conduzidos para coordenação as ofensas continuam. (P-9).

Completando o quadro sinistro de violência na escola, Abramovay (2003, p. 98) afirma o que é violência: "Magoar, agredir por falta de respeito". Para os jovens, são atos de violência por parte dos professores. Também são: a desvalorização do profissional professor; a insatisfação; a indiferença e o absentismo dos alunos; o despreparo do profissional (reflexo do medo); a falta de estímulos e interesse em educação continuada; a evasão escolar.

A outra forma é a violência contra a escola, que se apresenta como atos de vandalismo, incêndios e destruição e roubo ou furtos do patrimônio (paredes, carteiras, cadeiras, portas, cabos de fiação, cabos de telefone, materiais e equipamentos das instituições escolares e outros). 
Quanto à prática de violência na escola ou contra a escola, os resultados são apresentados na Tabela 24:

\section{Dados da Violência Praticada}

\begin{tabular}{|c|c|c|c|c|c|c|c|c|c|}
\hline \multirow{2}{*}{\multicolumn{2}{|c|}{$\begin{array}{l}\text { Alunos praticantes } \\
\text { de credos religiosos }\end{array}$}} & \multicolumn{4}{|c|}{ Pratiquei violência na escola } & \multicolumn{4}{|c|}{ Pratiquei violência contra a escola } \\
\hline & & Sim & $\%$ & Não & $\%$ & Sim & $\%$ & Não & $\%$ \\
\hline Católicos & 17 & 04 & $23 \%$ & 13 & $77 \%$ & 05 & $29 \%$ & 12 & $71 \%$ \\
\hline Evangélicos & 30 & 07 & $23 \%$ & 23 & $77 \%$ & 08 & $27 \%$ & 22 & $73 \%$ \\
\hline Espíritas & 05 & 02 & $40 \%$ & 03 & $60 \%$ & 03 & $60 \%$ & 02 & $40 \%$ \\
\hline Sem religião & 12 & 08 & $67 \%$ & 04 & $33 \%$ & 09 & $75 \%$ & 03 & $25 \%$ \\
\hline Outros & 02 & 01 & $50 \%$ & 01 & $50 \%$ & 01 & $50 \%$ & 01 & $50 \%$ \\
\hline
\end{tabular}

Fonte: Entrevistas realizadas entre maio e junho de 2013/Tabela 25.

\section{Alunos não Praticantes de Credo Religioso}

\begin{tabular}{lllllllllc}
\hline & & \multicolumn{3}{c}{ Pratiquei violência na escola } & \multicolumn{3}{c}{ Pratiquei violência contra a escola } \\
\cline { 5 - 9 } \multicolumn{1}{c}{ Credo } & & Sim & $\%$ & Não & $\%$ & Sim & $\%$ & Não & $\%$ \\
\cline { 1 - 5 } Católicos & 28 & 18 & $57 \%$ & 12 & $43 \%$ & 18 & $64 \%$ & 10 & $36 \%$ \\
Evangélicos & 05 & 03 & $60 \%$ & 02 & $40 \%$ & 03 & $60 \%$ & 02 & $40 \%$ \\
Espíritas & 01 & - & $0 \%$ & 01 & $100 \%$ & 01 & $100 \%$ & - & $0 \%$ \\
Sem religião & 12 & 09 & $75 \%$ & 03 & $25 \%$ & 10 & $83 \%$ & 02 & $17 \%$ \\
Outros & 02 & 01 & $50 \%$ & 01 & $50 \%$ & 01 & $50 \%$ & 01 & $50 \%$ \\
\hline
\end{tabular}

Fonte: Entrevistas realizadas entre maio e junho de 2013/tabela 26.

Embora 45 alunos se dizem católicos, somente 17 afirmam ser praticantes, o que representa $37,8 \%$ de entrosamento com o credo. Desses, $77 \%$ afirmam nunca ter praticado nenhum tipo de violência na escola. Já 23\% garantem já ter praticado. Dos 28 alunos católicos não praticantes, 57\% (18 alunos) afirmam ter praticado atos de violência, e 43\% (12 alunos) afirmam nunca ter praticado.

Analisando a comunidade católica praticante ou não, chegamos aos seguintes resultados: 22 alunos (49\%) afirmam ter praticado violência; 25 alunos $(55, \%)$ garantem nunca ter praticado atos de violência na escola. Quando a violência praticada é contra escola, o resultado encontrado foi: 23 alunos (51\%) afirmam já ter praticado atos de violência contra a escola; 22 alunos (49\%) não praticaram.

No que tange aos alunos que se dizem evangélicos de um total de 35 alunos, 30 se denominam frequentes/praticantes. Desses, 10 alunos $(28,6 \%)$ afirmam já ter praticado atos de violência na escola e 25 alunos $(71,4 \%)$ assumem a postura e afirmam nunca ter participado violência. Quando a violência praticada é contra a escola, os evangélicos se 
posicionam da seguinte maneira: 11 alunos $(31,4 \%)$ afirmam já terem praticaram violência contra a escola; 24 alunos $(68,6 \%)$ negam ter praticado essa modalidade de violência.

Dos 12 alunos que se manifestam sem religião, 9 alunos (75\%) afirmam ter praticado atos de violência na escola; 3 alunos (25\%) afirmam não ter praticado atos de violência. Quando a violência é contra a escola, os resultados dos alunos sem religião são os seguintes: 10 alunos (83\%) já praticaram violência contra a escola; 2 alunos (17\%) afirmam nunca ter praticado.

Os dados citados ajudam a confirmar nossa primeira hipótese: A composição conceitual de violência dos alunos do ensino fundamental é influenciada pelas significações sociais.

Nesse contexto podemos afirmar que o indivíduo sofre a influência direta da família, da escola, $[. .$.$] , da religiosidade. Como apontam diversos estudos, essa última apresenta uma$ influência significativa sobre o comportamento social dos indivíduos e é vista como incentivadora da boa "postura social". Talvez isso possa justificar os dados apresentados, mostrando que, quanto mais inseridos os alunos estiverem nos movimentos religiosos, menos violência eles praticam no ambiente escolar.

Para Durkheim (1982), isso acontece por ser a religião "uma instituição social produtora de valores morais e identitários" (apud SETTON, 2008, 8). Afirma ainda que a "religião oferece aos indivíduos elementos para a elaboração de idéias, pensamentos e representações sociais que possibilitam compreender o mundo por meio do conhecimento religioso". Bourdieu (1982) chamou a cultura transmitida à criança por seus pais, e grupos sociais, como por exemplo a religião, de "capital cultural".

Mesmo sabendo que a religião (religiosidade) pode contribuir para a formação do espírito humano e ter um papel fundamental na formação do sujeito, cabe-nos alertar que não é a religião o único elemento social responsável pela construção e pela mantença do conceito e da prática da violência.

Na busca de construir uma sustentação para nossa terceira hipótese - que era averiguar se a cultura de paz no ambiente escolar estava diretamente associada à visão de Deus que cada aluno tem constituída nas relações sociais através da família e da religiosidade, e se nesse contexto Deus pode ser visto como fator de contenção a violência -, procuramos apreender como era a relação dos nossos alunos com o Sagrado. E também qual a imagem de Sagrado 
que eles tinham constituído. E verificar como transformar isso em paz para o ambiente escolar.

O primeiro passo foi pedir aos alunos que definissem violência, paz e Deus. E o link que podemos fazer dessas três palavras juntas e em ação é MUDANÇA.

Percebe-se que alguns dos estudantes iniciam seu primeiro contato com Deus a partir da família, seu primeiro grupo social, e mais tarde solidificada na religião. Exemplo disso é que apenas $12 \%$ dos entrevistados afirmaram não ter religião. Isso significa dizer que $88 \%$, de uma forma direta ou indireta, têm contato com a religiosidade. E entre aqueles que se dizem praticantes, o índice de violência é bem menor.

\section{Cultura de Paz e Violência Escolar no campo empírico}

A cultura de paz é uma proposta para que as relações humanas sejam entremeadas pelo diálogo, pela tolerância, pela consciência da diversidade dos seres humanos e de suas culturas.

Quando analisado no ambiente escolar, muitos autores consideram o sistema educativo uma estrutura violenta em si mesmo e discutem sobre a possibilidade de educar para a paz na atual organização educacional.

É interessante observar que tanto a paz como a violência são processos construídos a partir das relações entre seres (des)humanos, podendo, então, serem ensinados e/ou aprendidos (GUIMARÃES, 2004). Nessa direção, é fundamental (re)pensarmos as ações que devem ser construídas diariamente dentro das unidades escolares.

A valorização da diferença, da identidade dos sujeitos, é um passo importante para a promoção de uma educação para a paz. Refere Correa (2003, p. 97):

O direito à identidade é um aspecto essencial na educação para a paz; uma cultura e uma sociedade de paz só serão possíveis desde o reconhecimento e integração das diferentes culturas que a conformam. Por isso, hoje, reforçamos a reivindicação da diferença e a valorização da diferença no sentido cultural e étnico para o enriquecimento da humanidade. 
A escola como um espaço de diversidade deve promover um ambiente em que as distintas identidades se manifestem e que os alunos se sintam orgulhosos de sua identidade cultural.

No decorrer da pesquisa vimos que no dia a dia da escola-campo é comum a manifestação de queixas por parte dos profissionais da educação, que apontam a dificuldade de ministrar suas aulas sem antes perder preciosos minutos resolvendo questões de indisciplina, tentando controlar as conversas paralelas e trazer o aluno para o universo da aula, mediando conflitos entre alunos que na maioria das vezes partem para o xingamento e até mesmo para a violência física. Além desses, existem outros gargalos com os quais os professores são obrigados a conviver, como por exemplo a falta de compromisso com as atividades, ou seja, a maioria dos alunos não faz as tarefas, não valorizam o espaço escolar. Eles arrastam e derrubam cadeiras e mesas, picham as paredes, quebram os vidros, destroem as tomadas.

Os problemas não se limitam somente à sala de aula. O grupo gestor fez queixas em relação ao corpo docente, como faltas de professores, atrasos, não cumprimento de prazos, aulas não planejadas ou de má qualidade, falta de respeito às regras coletivas da instituição. E para completar o quadro, os professores muitas vezes manifestam insatisfação com relação ao trabalho dos seus líderes, reclamando da ausência, de falta de "pulso firme" ou de excesso de autoritarismo.

Tudo isso demonstra a fragilidade das relações sociais estabelecidas entre os agentes no ambiente escolar e aponta para a necessidade de políticas de combate. Percebe-se a prática isolada do uso de combinados por parte de alguns professores, que tentam firmar pactos de convivência ou acordos coletivos com os alunos. No entanto, há um enfraquecimento, por não haver um discurso unânime estruturado em torno dos combinados.

Tal realidade talvez seja comum a muitas escolas brasileiras, que encontram dificuldades de estabelecer um padrão de autoridade sobre o cumprimento das normas, e nesse contexto, muitas vezes, a visão autoritária tende a utilizar o medo como forma de manter o controle, com uma forte tendência à punição.

Como sugestão aponta-se uma reformulação na ideia de fazer combinados, que devem trazer uma solução não repressiva para o problema da indisciplina e da crise de autoridade do professor. No combinado, devem-se construir coletivamente os "acordos" necessários para 
criar e manter um convívio de respeito e solidariedade entre profissionais, alunos e pais e, com isso, prevenir os problemas de violência e indisciplina na escola.

Analisando alguns aspectos extraescolares, a pesquisa demonstrou, ainda, que $74 \%$ dos alunos não gostam do bairro em que moram, não possuem nenhuma identificação positiva com o espaço. Esse dado é um indicador para compreendermos a crescente onda de violência vivenciada na unidade escolar.

Sobre isso, o pesquisador norueguês John Galtung (1975 apud MALDONADO, 1997) constata que, se a violência direta desapareceu, traços de violência estrutural ainda subsistem no sistema educativo. Para ele, é provavelmente ingênuo pensar que possa haver uma autêntica educação para a paz dentro dos sistemas escolares da maior parte dos países sem que isso repercuta de alguma maneira em seus sistemas.

Para o educador espanhol Xesús Jares, “educar para a paz deve fazer-nos conscientes em primeiro lugar da contradição, às vezes, insolúvel, que supõe educar para a paz em meio que por sua natureza e funcionalidade é violento" (1999 apud CORREA, 2008, p. 175). Para o francês Jean-Marie Muller (1995), a educação para a não violência passa pela não violência da educação.

Aqueles que se assustam com as múltiplas manifestações de violência na escola não percebem que a escola, de uma maneira geral, caracterizou-se como um espaço de violência. Em primeiro lugar, física. Não podemos esquecer que há mais de cinquenta anos, em muitos lugares, eram comuns as punições físicas. Depois, que ensinar e aprender sempre estiveram associados a punir e premiar. Enfim, que na escola sempre se processou a racionalização das violências, de todo tipo de violência, sejam físicas, psíquicas e simbólicas. Trata-se, portanto, de começar a compreender a própria contribuição da escola no processo de formação e consolidação desta razão bélica, começando a falar da violência da escola. Sobretudo, é preciso perguntar em que medida os discursos e as análises trabalham não apenas a violência expressa na educação, mas a violência produzida pela educação, ultrapassando o discurso descritivo sobre a violência (nos meios de comunicação, em sala de aula, na juventude, etc.) e abrindo espaço para uma crítica e autocrítica da própria educação como instrumento de violência. 


\section{Concepção de Paz}

\section{O que é Paz?}

Não necessariamente é a ausência de guerra, mas é popularmente definida como tranquilidade,

calma. Defino como aquilo que desprende o pensamento do homem para qualquer tipo de problema.

É um ato de prazer, de conformidade consigo e para com o meio. A paz nos faz ficar tranquilos com a nossa consciência, com nossa alma e com Deus.

Uma simples palavra que surge muito em seus efeitos. A paz é um momento tranquilo, reunido com a família. Significa amor, carinho, afeto, cuidado e respeito.

É amor consigo mesmo, harmonia, carinho, família, amigos, saúde. Dormir e acordar bem, junto com Deus.

É quando você se sente leve e tranquila. Quando você está com sua família, todos unidos e felizes.

É um ato de alegria, que existe na vida de quem está com Deus.

É um estado de espírito. Quem está em paz consigo mesmo, transmite paz.

É um sentimento muito importante, pois se vive em paz, e tem paz em sua casa, você também

promoverá a paz.

É você sentir bem consigo mesmo e em meio aos outros.

É tudo de bom. É a esperança que todos nós temos em termos um mundo melhor.

É estar em paz consigo e viver bem com todos.

É ter Deus no coração e viver com igualdade, compreensão, sentimento e harmonia.

É todos viverem em harmonia, estar de bem com tudo, com todos e com Deus.

É sentir-se feliz, se não há Paz deve buscá-la em Deus.

É a tranquilidade, felicidade e realizações. É cercar-se de coisas e sentimentos bons.

É quando vejo toda a família unida. Aí está em paz com a família e com Deus.

É um sentimento de liberdade, sensação de estar perto de Deus.

É a tranquilidade que sentimos quando estamos perto das pessoas que amamos.

É o sonho de cada ser humano.

É o que todos queremos e o que mais nos falta. Um estado de estarmos sempre na presença de

Deus.

É um sentimento de bem-estar. Pai, mãe, irmãos família.

É um estado de alma e que depende de cada indivíduo para ser alcançado.

Fonte: Entrevistas realizadas entre maio e junho de 2013/Tabela 29.

Hoje, no terceiro milênio, a busca pela paz é uma das grandes preocupações que envolvem a opinião pública, a esfera política, os grupos religiosos e instituições diversas, como por exemplo a escola. A busca de responder a esta preocupação socialmente generalizada fez e faz surgir estudos como o nosso, que transita no campo interdisciplinar e permite uma reflexão sobre paz, violência e conflitos, com o intuito de cunhar conceitos e objetivos metodológicos de ação prática.

Para Kant (2004, p. 54), é preciso um esforço consciente e racional dos governantes e governados para controlar e extinguir as causas das guerras. Esse esforço se daria, 
principalmente, num aperfeiçoamento das instituições humanas, como o direito, pois seriam elas as garantidoras e mantedoras da paz.

Para isso, no campo de pesquisa procuramos entender a concepção de paz a partir da ótica dos sujeitos e perceber quais fatores colaboraram para construção significativa desses conceitos.

\section{Considerações Finais}

O primeiro eixo da investigação foi "identificar e descrever como os alunos do $9^{\circ}$ ano percebem o convívio escolar, tanto no que diz respeito aos conflitos não resolvidos como em relação à sua percepção sobre o funcionamento da escola, a organização do estabelecimento, a aplicação e o cumprimento das regras, a qualidade das relações interpessoais e, ainda, suas concepções acerca da resolução dos conflitos".

Nas falas dos sujeitos percebe-se que há diversos tipos de ambiências violentas, não se podendo restringir a violência a um único fator. Esse dado ficou evidente nos danos físicos ou simbólicos sofridos pelos indivíduos ou grupos pertencentes à escola. Evidencia-se ainda que, na escola, as violências envolvem os integrantes desta, tanto como agentes do ato quanto como vítimas. A violência física é a face mais explícita desse fenômeno, caracterizada por brigas, ameaças, principalmente feitas pelos alunos. Observou-se, também, que as brigas são banalizadas e, muitas vezes, excitadas pelos colegas.

Tais situações mostram a fragilidade do ambiente escolar e podem ser explicadas de várias maneiras. Talvez, porque a escola não é um lugar "agradável" que proporciona aos seus integrantes o prazer de ali estarem. Outra justificativa, talvez seja a falta de perspectiva e incerteza com o futuro, na visão dos estudantes. Diante disso, as violências são explicadas como uma alternativa para as frustrações sofridas: diante do sentimento de insegurança, de injustiça, do não reconhecimento, do racismo, a discriminação eclode em experiências violentas para esses jovens.

Neste contexto de uma convivência escolar tensa, surgem atos de vandalismo, na unidade escolar, que expressam de forma clara o sentido de não pertença ao espaço. Embora 
as discussões do tema em pauta, nos espaços acadêmicos e entre os órgãos educacionais, corroborem a necessidade de projetos educativos voltados para a proximidade dos sujeitos da escola, indicando proposições de trabalho voltadas para um novo modelo formativo de alunos e professores, verifica-se uma dissonância entre o que é proposto e a prática do cotidiano escolar. Um dos aspectos que contribui para não efetivação dessa proposta é a ausência de espaços pedagógicos de escuta para os alunos.

Dar voz aos estudantes, discutir com eles suas expectativas, expor os objetivos educacionais, elaborar coletivamente as normas são ações que podem colaborar, de forma significativa, para a formação de um ser social capaz de falar, de respeitar o outro.

Essa é uma informação que a literatura tem procurado mostrar, sublinhando que o maior envolvimento dos alunos com a escola resulta em atividades escolares e de aprendizagem mais positivas.

Entretanto, o quadro esboçado aqui mostra que a unidade escolar pesquisada vem sofrendo com as dificuldades em adotar medidas preventivas e resolver as violências presentes no cotidiano escolar. As hipóteses levantadas quanto à composição conceitual de violência dos alunos e suas influências pelas significações sociais - de que determinados contextos propiciam o desenvolvimento de manifestações de violência (A-1), e essa, quando colocada em ação, revela aos atores sociais o poder de seu uso (A-2) - foram ratificadas na pesquisa de campo. Observou-se que a escola pesquisada, a exemplo de muitas outras no país, apresenta-se em vários momentos como um espaço de exclusão social, pois reproduz as desigualdades sociais e exclui os alunos por suas dificuldades de aprendizagem, adotando práticas pedagógicas e disciplinares autoritárias. São exemplos a constituição de turmas formadas por alunos repetentes e com alto histórico de indisciplina, aplicar normas construídas sem a participação da comunidade escolar vindas de cima para baixo pontuando se aqui a retirada do intervalo no turno vespertino que para os alunos é uma espécie de punição. Atitudes como essas, arraigadas de autoritarismo institucional conforme os depoimentos apresentados podem resultar em atos de violência como uma forma de protesto e expressão crítica contra essa violência simbólica oriunda da escola.

Os principais resultados apontam que a violência na escola promove entre os alunos o desinteresse pelos estudos e insegurança, e entre os professores a perda de estímulo pelo trabalho e medo. Os atores não percebem a escola como um ambiente de mediação de 
conflitos. Apontam-se como proposta para a constituição de escola cidadã a formação dos professores e o desenvolvimento de uma cultura da paz que trabalhe os valores sociais e humanos, a ética, a solidariedade, o respeito aos direitos humanos. Por isso, foi fundamental voltar à reflexão para as concepções de ser humano como protagonista principal desses comportamentos de violência, de paz, amor e entendimento. Conclui-se, na observação, que tanto a paz como a violência são processos construídos a partir das relações entre seres (des)humanos, podendo, então, serem ensinados e/ou aprendidos. Nessa direção, é fundamental (re)pensarmos as ações que devem ser construídas diariamente dentro das unidades escolares.

\section{Referências}

ABRAMOVAY, Miriam (Coord.). Escolas de paz. Brasília: UNESCO; Governo do Estado do Rio de Janeiro/SEE/UFRG, 2001.

Enfrentando a violência nas escolas: um informe do Brasil. In: FILMUS, Daniel et al. Violência na escola: América Latina e Caribe. Brasília: UNESCO, 2003.

Cotidiano das escolas: entre violências. Brasília: UNESCO no Brasil, 2005. Disponível em: <http://unesdoc.unesco.org/images/0014/001452/145265POR.pdf.> Acesso em: fev. 2014.

ABRAMOVAY, Miriam; CASTRO, Mary Garcia. Caleidoscópio das violências nas escolas. Brasília: Missão Criança, 2006.

ABRAMOVAY, Miriam et al. Gangues, galeras, chegadas e rappers: juventude, violência e cidadania nas cidades da periferia de Brasília. Rio de Janeiro: Garamond,1999.

BERGER, P. O dossel sagrado: elementos para uma teoria sociológica da religião. São Paulo: Paulus, 2003.

BEYER, Peter. A privatização e influência pública da religião na sociedade global. In: . Cultura global: nacionalismo, globalização e modernidade. Petrópolis, vozes, 1998. p. 395-419.

BOURDIEU, Pierre. O campo científico. In: ORTIZ, R. Pierre Bourdieu. São Paulo: Ática, 1994. (Coleção Cientistas Sociais

BOURDIEU, Pierre et al. A miséria no mundo. 5. ed. Petrópolis: Vozes, 2003. 
CORRÊA, Rosa L. Teixeira. Cultura, cultura brasileira e religiosidade. Curitiba, PR: Ibpex, 2008

CORRÊA, Rosângela Azevedo. Cultura, educação para, sobre e na paz. In: MILANI, Feizi M.; JESUS, Cássia Dias P. de (Org.). Cultura de paz: estratégias, mapas e bússolas. Salvador: INPAZ, 2003.

DEBORD, Guy. A sociedade do espetáculo. Rio de Janeiro: Contraponto, 1997.

FORACCI, Marialice M.; SOUZA MARTINS, José. Sociologia e sociedade: leituras de introdução à sociologia. Rio de Janeiro; São Paulo: Livros Técnicos e Científicos, 1980.

GALIMBERTI, Umberto. Rastros do sagrado: o cristianismo e a dessacralização do sagrado. São Paulo: Paulus, 2003.

GUIMARÃES, Marcelo Rezende. Cidadãos do presente: crianças e jovens na luta pela paz. São Paulo: Saraiva, 2002.

Um mundo novo é possível: dez boas razões para educar para a paz, praticar a tolerância, ser solidário, promover os direitos humanos. São Leopoldo: Sinodal, 2004.

KANT, Emmanuel. A paz perpétua. Porto Alegre: L\&PM Editores, 1989. . (Org.). A paz perpétua: um projeto para hoje. São Paulo: Perspectiva, 2004.

OTTO, Rudolf. O Sagrado. Lisboa: Edições 70, 2005.

RIZZUTO, Ana Maria. O nascimento do Deus vivo: um estudo psicanalítico. São Leopoldo: Sinodal/EST, 2006.

SETTON, Maria da Graça Jacintho. As religiões como agentes da socialização. Cadernos CERU, São Paulo: USP, v. 19, p. 15-25, 2008.

Como citar este artigo (Formato ABNT):

PURIFICAÇÃO, Marcelo M.; CATARINO, Elisângela M.; QUADROS, Eduardo G. A Violência Escolar e Paz numa perspectiva Subjetiva: um estudo a partir da vivência e religiosidade de alunos do último ano do Ensino Fundamental. Id on Line Revista Multidisciplinar e de Psicologia, Julho de 2017, vol.11, n.36, p.327-342. ISSN: 1981-1179.

Recebido: 17.07.2017

Aceito: 18.07 .2017 